\section{International Scientific Journal Theoretical \& Applied Science}

p-ISSN: 2308-4944 (print) e-ISSN: 2409-0085 (online)

Year: $2014 \quad$ Issue: $10 \quad$ Volume: 18

Published: $30.10 .2014 \quad$ http://www.T-Science.org

SECTION 7.Mechanics and machine construction.
Aleksey Sergeevich Sevostyanov Undergraduate student

Togliatti State University, Russia sevalexey@yandex.ru

Aleksey Aleksandrovich Lukyanov Undergraduate student

Togliatti State University, Russia a.lukyanov@tehnomasch.ru

Igor Nikolaevich Bobrovskij

Ph.D., chief of laboratory

Togliatti State University, Russia bobri@yandex.ru

\title{
MODERN STATUS OF RESEARCH IN THE FIELD OF MICRORELIEF APPLICATION IN RUSSIAN SCIENCE
}

Abstract: In this paper modern Russian experience in the application of microrelief on the surface of the parts is presented. The main directions of further development of research are determined.

Key words: microrelief, surface plastic deformation, honing.

Language: Russian

Citation: Sevostyanov AS, Lukyanov AA, Bobrovskij IN (2014) MODERN STATUS OF RESEARCH IN THE FIELD OF MICRORELIEF APPLICATION IN RUSSIAN SCIENCE. ISJ Theoretical \& Applied Science 10 (18): 82-84. doi: http://dx.doi.org/10.15863/TAS.2014.10.18.17

\section{СОВРЕМЕННОЕ СОСТОЯНИЕ ИССЛЕДОВАНИЙ В ОБЛАСТИ НАНЕСЕНИЯ МИКРОРЕЛЬЕФА В ОТЕЧЕСТВЕННОЙ НАУКЕ}

Аннотация: В работе представлен современый отечественный опыт в области нанесения микрорельефов на поверхности деталей. Определень основные направления дальнейшего развития исследований.

Ключевые слова: микрорельеф, поверхностно-пластическое деформирование, хонингование.

Исследования финишной отделочноупрочняющей обработки поверхностнопластическим деформированием (ППД) как метода нанесения микрорельефа активно исследовались в 80ые годы и полученные результаты свидетельствуют о необходимости внедрения данного метода нанесения микрорельефов в промышленность. К сожалению, трудности связанные с переходным периодом в экономике и последующая приостановка производства отечественного обрабатывающего оборудования пропорционально снизили потребность в НИР и ОКР для машиностроения (крайне показательно в данном случае история развития действующего ГОСТ-2789 «Шероховатость поверхности», обновлявшегося в $45,51,59,73$ и последний раз в 81 годах), в результате остались не использованными накопленные за годы работы технические компетенции отечественных научных школ [10].

В настоящее время продоложаются отдельные исследования в области нанесения микрорельефа, направленные на различные задачи. Невозможно оценить текущий уровень внедрения технологий нанесения микрорельфа методом выглаживания, т.к. данные сведения отсутствуют в открытом доступе, однако примечательно, что сам принцип формирования микрорельфа на поверхности деталей машин широко применяется [2, 4].

Например, несмотря на проведенный основоположником данного направления исследований Ю.Г. Шнейдером успешный эксперимент [11] по нанесению микрорельфа на гильзу цилиндра двигателя с помощью вибрационного выглаживания, в настоящее время для формирования микрорельфа используется иная технология - платовершинное хонингование, и на ключевых предприятиях нашей страны (ОАО «АВТОВАЗ») применяются не отчественные разработки, а дорогостоящие импортные станки для обработки хонингованием.

Работа выполненная Барацем Я.И. и др. в 2007 году [9] при поддержке гранта РФФИ №1008-00669-а позволила заложить основы высокопроизводительной технологии нанесения микрорельфа, была проведена апробация данной технологии на примере обработки внутренней 
поверхности блока цилиндров дизельных двигателей. Суть эксперимента состояла в исследовании влияния изменения угла наклона канавок и относительной площади канавок на износ обработанной поверхности, при этом

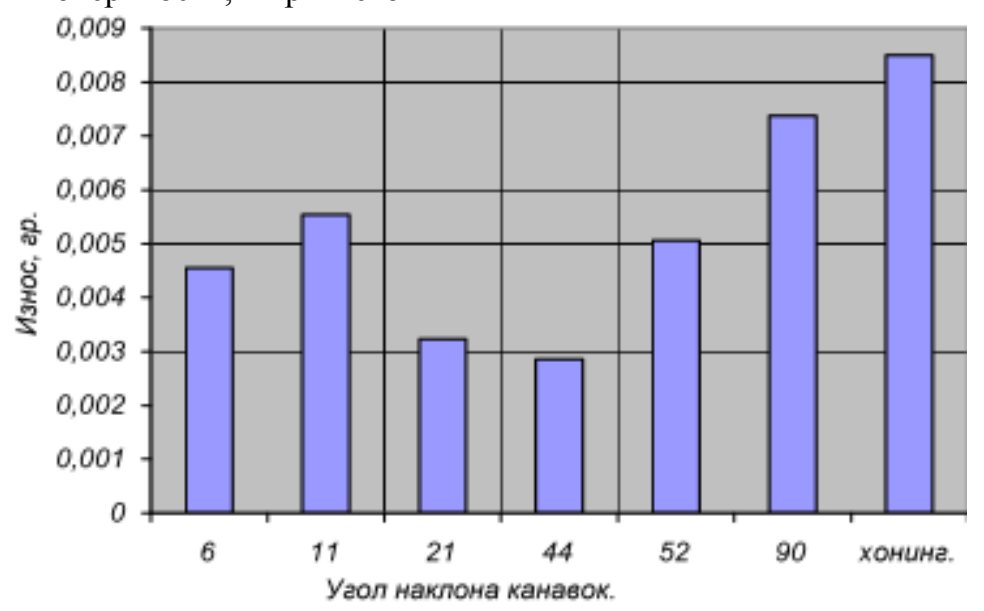

обработка с нанесением микрорельфа с уголом равным 44 градусам показала наименьший износ канавок (по сравнению с хонингованием меньший в 3 раза, рис 1).

Рисунок 1 - Влияние угла наклона канавок на интенсивность износа [9].

Однако, обработка по данной технологии потребовала дополнительной притирки поверхности для исключения из микрорельфанаплывов, являющихся следствием пластической деформации металла. Данная работа вновь продемонстрировала перспективность применения нанесения микрорельфа с помощью ППД на детали машин.

Для обеспечения реализации процессов нанесения микрорельефа на современном оборудовании с ЧПУ в Санкт-Петербургском государственном университете информационных технологий [7], механики и оптики были формализованы механизмы формирования микрорельфа на поверхности деталей машин в виде ряда зависимостей, связывающих технологические параметры процесса и параметры получаемой микрогеометрии. Полученные зависимости были апробированы с помощью ПО имитирующего ЧПУ промышленного станка - WinNCSINUMERIK 840D MILL55. Разработанный алгоритм позволяет увидеть все рабочие перемещения и проконтролировать возможность столкновения установочно-зажимного приспособления и заготовки. Отмечено, что наибольшее влияние на характер микрорельфа оказывает парамері отражающий смещение второй кривой микрорельфа относительно первой, т.е. отражающий степень их взаимного пересечения (рис. 2).

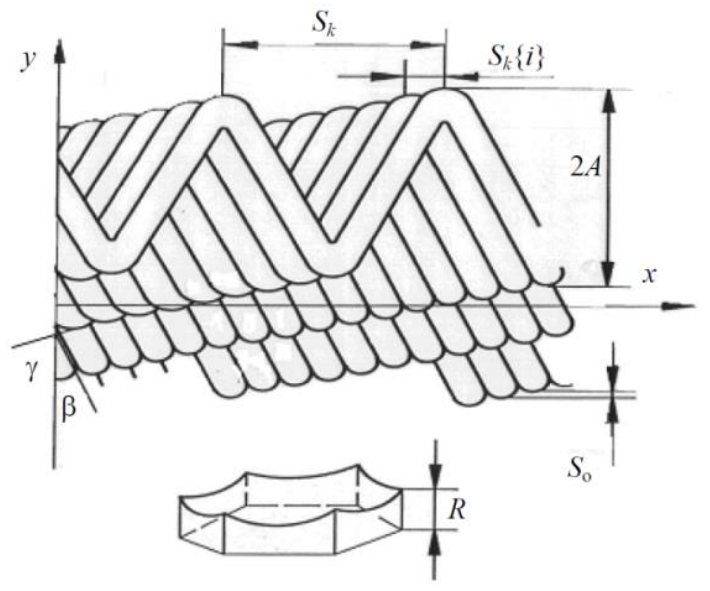

Рисунок 2 - Параметры регулярного микрорельфа[6].

Данная работа авторов отражена в статье [6]. Авторами была разработана программа АСОРМР позволяющая по заданным технологическим параметрам рассчитать параметры микрорельефа обработанной поверхности на основе накопленных за годы работы последователями Ю.Г. Шнейдера данными. Реализация полученных данных осуществляется формированием после 
внесения исходных данных - амплитуды осциллирующего движения инструмента, освего шага неровости, ширины канавок, отношения числа оборотов заготовки к числу двойного хода инструмента, txt-файла содержащего команды воспринимаемые большинством современных станков с ЧПУ. Однако авторы отмечают, что предстоит большая работа по созданию метрологического обеспечения для производственного использования результатов работы.

В статье группы исследователей под руководством Кузнецова В.П. из Курганского государственного университета [8] определено влияние различных типов микрорельфов на маслоемкость и сопряженные с ней функциональные параметры прирабатываемость, сопротивление износу, задиру и т.д. При этом выступы выделенного металла высотой соизмеримой $\mathrm{c} \quad \mathrm{Rz}$ не уничтожались, т.к. авторы отмечают, что известные способы обработки с нанесением микрорельфа позволяют нанести только выпуклый или вогнутый микрорельф и невозможно получить функциональные свойства поверхности как после обработки плосковершинным хонингованием. Обработку выполняли в два перехода за один установ: хонбруском и цилиндрическим выглаживающим инструментом специальной конструкции [5]. Данный способ позволяет совместить достоинства обработки хонингованием и ППД, когда после обработки ППД остается микрорельф с операции хонингования, но сглаживаются «острые» (с достаточно малым углом при вершине) выступы микрорельфа. В заключении статьи отмечено, что предложенная технология является новаторской и в большей степени представляет собой ноу-хау.

Проведенный анализ подтверждает, что методы ППД могут быть не только альтернативой методам хонингования, но и позволяют более полно контролировать процесс формирования микрогеометрии обработанных деталей $[1,3]$ (по критерию количества регулируемых параметров, которые возможно задавать априорно), а учитывая сформированный научный задел отечественных научных школ дальнейшее развитие данных работ с привлечением заинтересованных индустриальных партнеров позволит повысить конкурентоспособность и энергоэффективность работы узлов машин, изготавливаемых в Российской Федерации.

\section{References:}

1. Bobrovskij NM, Mel'nikov PA, Ezhelev AV, Bobrovskij IN (2012) Ustrojstvo dlya giperproizvoditel'noj finishnoj obrabotki poverhnostej detalej vyglazhivaniem. Izvestiya Samarskogo nauchnogo centra Rossijskoj Akademii Nauk. Vol.14, no.6 (part 1). pp. 93-96. URL:http://www.ssc.smr.ru/media/journals/izvest ia/2012/2012 6 6 93 96.pdf (accessed: 29.10.2014).

2. Brzhozovskij BM, Zaharov OV (2010) Obespechenie tehnologicheskoj nadezhnosti pri bescentrovoj abrazivnoj obrabotke. Saratov, Saratovskij gosudarstvennyj tehnicheskij universitet, 216.

3. Gorshkov BM (2005) Povyshenie tochnosti tehnologicheskih obrabatyvayuschih sistem s sostavnymi staninami metodom avtomaticheskoj kompensacii ih deformacij: avtoref. diss. Ph.d. Samara: Samarskij gosudarstvennyj tehnicheskij universitet, 35.

4. Ezhelev AV, Bobrovskij IN, Lukyanov AA (2012) Analiz sposobov obrabotki poverhnostnoplasticheskim deformirovaniem. Fundamental'nye issledovaniya. No 6 (part 3). pp. 642-646. URL: http://elibrary.ru/download/36394326.pdf (access date: 29.10.2014).

5. (2008) Vyglazhivatel' dlyamnogooperacionnyhtokarno-frezernyhcentrov: patent Russian Federation napoleznuyu model' No.70178 U1,IPC
B24B 39/02. Il'ichev SA, Kuznecov VP, Gubanov VF, Gorgoc VG; Opubl.B.I. 2008. No.2.

6. Golubchikov MA, Kuz'min YP (2010) Modelirovanie processa vibronakatyvaniya. Izvestiya vysshih uchebnyh zavedenij. Priborostroenie. Vol. 53, no 8, pp. 26-29.

7. Golubchikov MA, Kuz'min YP (2012) Obrazovanie regulyarnogo mikrorel'efa na stanke s chislovym programmnym upravleniem. Izvestiya vysshih uchebnyh zavedenij. Priborostroenie.Vol. 55, no 9, pp. 34-38.

8. Kuznecov VP, Gorgoc VG, Dmitrieva OV (2009) Inzheneriya ploskovershinnogo regulyarnogo mikrorel'efa poverhnosti pri mnogocelevoj obrabotke detalej. Vestnik UGATU. Ufa: UGATU. Vol. 12, no 4(33). pp. 113-115.

9. Milovanova LR (2007) Uluchshenie jekspluatacionnyh svojstv poverhnostej otverstij metodom poverhnostno-plasticheskogo deformirovaniya s obrazovaniem regulyarnogo mikrorel'efa.Vestnik Saratovskogo gosudarstvennogo tehnicheskogo universiteta. No 2(25), issue 2. pp. 60-64.

10. (1981) Sherohovatost' poverhnosti. Parametry, harakteristiki i oboznacheniya: GOST 278973. Vveden 1975-01-01, izmenen 1981-01-01. Moscow: Izdatel'stvo standartov, pp. 1-7.

11. Shnejder YG (1982) Jekspluatacionnye svojstva detalej s regulyarnym mikrorel'efom. Leningrad: Mashinostroenie: 248 